\title{
Um Estudo sobre a Influência de Accruals na Correlação entre o Lucro Contábil e a Variação do Capital Circulante Líquido de Empresas
}

\author{
Romualdo Douglas Colauto \\ Ilse Maria Beuren
}

\section{Resumo}

A presença de accruals é comum no modelo contábil. Usados no sentido de provisões e estimativas, representam os elementos do resultado que, embora pelo regime de caixa já tenham sido efetivados, ainda não se atribuem na apuração ou do regime de competência. $O$ fornecimento de uma medida do lucro para indicar o desempenho da empresa faz-se necessário para balizar o processo de tomada de decisões. Nessa perspectiva, o estudo delineado exploratório, com abordagem quantitativa, buscou analisar a influência dos accruals, provenientes da depreciação, na correlação entre o lucro contábil e a variação do capital circulante líquido. A população alvo para o estudo foram as empresas consideradas as 500 Maiores e Melhores Empresas do Brasil, conforme pesquisa realizada pela Revista Exame em 2002. Considerando-se, primeiro, uma amostra de 50 empresas selecionadas por acessibilidade, selecionaram-se intencionalmente 30 empresas para coleta e análise dos dados. Os resultados da pesquisa mostraram que houve baixa correlação negativa, quando a depreciação é reduzida do lucro contábil e baixa correlação positiva pela reintegração da depreciação ao resultado residual, significando que o desconhecimento do processo contábil pode influenciar as decisões, quando se considera o lucro como medida para determinar a eficiência empresarial.

Palavras-chave: accruals; lucro contábil; variação do capital circulante líquido.

\begin{abstract}
The accruals appear in the accounting model commonly. Used as provisions or estimations they represent the elements of the result required by the cash basis, they are not attributed of determination in the matching basis. By conceiving income as an important signal in the process of decisionmaking, the supply of a profit measure as an indicator of a company's performance becomes essential. In this way, this study is delineated as exploratory with a quantitative approach analyze the influence of accruals brought forth by depreciation in the correlation of accounting income and the net working capital variance. The 500 Brazilian greatest companies presented in research carried out by the accounting and business magazine Revista Exame (2002) were used as the target population of this study. The sample of 50 companies was firstly selected out of accessibility, and, later on, 30 was selected intentionally, heading for the collection and analysis of data. The results of this research show that there is a low negative correlation when depreciation is reduced from the accounting profit and that there is a low positive correlation when depreciation is reintegrated to the residual result. This means that the unawareness of the accounting process may influence decisions when regarding income as a measure to determine business efficiency.
\end{abstract}

Key words: accruals; accounting income; net working capital variance. 


\section{Considerações Preliminares}

O lucro tem sido considerado importante medida para determinar a eficiência empresarial. O objetivo principal de sua divulgação é apoiar os usuários internos e externos na tomada de decisões estratégicas e táticas. O Financial Accounting Standard Board [FASB], publicou em 1978 o pronunciamento SFAC $\mathrm{n}^{\circ} 1$ Statements of Financial Accounting Concepts onde menciona que os investidores e credores freqüentemente recorrem ao lucro para avaliar a capacidade de geração de resultados, predizer resultados futuros e analisar o risco do investimento (Hendriksen \& Van Breda, 1999).

O conhecimento de medidas distintas do lucro pode ser útil para finalidades diversas, mas acredita-se haver alguma vantagem na aceitação de um conceito abrangente do lucro para efeito de divulgação externa. De acordo com Hendriksen e Van Breda (1999), o lucro é abordado nos enfoques pragmático, semântico e sintático. O enfoque pragmático do lucro está associado aos processos decisórios de investidores e credores, às reações dos preços de títulos divulgados em mercados organizados, às decisões de investimento dos administradores, e às reações de feedback na gestão das empresas por meio de seus contadores e administradores. No enfoque semântico, os lucros representam o funcionamento eficiente da empresa, considerando as relações com realidades econômicas subjacentes. Pressupõe-se que o funcionamento eficiente de uma empresa afeta tanto uma série de dividendos correntes quanto o uso do capital aplicado para a geração de fluxos futuros de dividendos.

No enfoque sintático, o lucro baseia os princípios e regras em premissas que podem não ter relação com fenômenos reais ou efeitos comportamentais. De acordo com Hendriksen e Van Breda (1999, p. 200), os lucros fundamentam-se em convenções e regras que devem ser lógicas e coerentes, muito embora possam não se ajustar perfeitamente às noções de lucro dos economistas. As convenções e regras se tornam lógicas e coerentes, porque se alicerçam em premissas e conceitos desenvolvidos a partir da prática existente. Entretanto conceitos como realização, vinculação, regime de competência e alocação de custos só podem ser definidos em termos de regras precisas, porque não possuem contrapartidas no mundo real.

O lucro no enfoque sintático mantém uma certa dificuldade de aceitação, por não se ajustar perfeitamente às noções de lucro econômico e estar parametrizado nos Princípios Contábeis Geralmente Aceitos. Ao parametrizar-se nos Princípios Contábeis e por enfatizá-lo com tanta freqüência, os contadores tendem a aceitá- 
lo como possuidor de interpretação, não admitindo que não possui significado fora do limitado papel na lógica da estrutura contábil (Hendriksen \& Van Breda, 1999). A ausência de significado pode ser um motivo pelo qual os estudiosos têm encontrado dificuldades para captar os conceitos contábeis, dando significado interpretativo a conceitos que não possuem relação com objetos e eventos reais.

O FASB (1978) no SFAC n ${ }^{\circ} 1$ pressupôs que o lucro contábil, na ótica de medida do desempenho da empresa, pode ser utilizado para predizer fluxos de caixa futuros. Todavia, segundo Hendriksen e Van Breda (1999), apesar do lucro contábil ser relevante para o processo de tomada de decisões de investidores e credores, não se tem provado empiricamente a validade destas suposições teóricas. Citam Bedford (1971), ao mencionar que os leitores de relatórios financeiros podem compreender a acepção do lucro contábil, mais facilmente, por meio do conhecimento do modo pelo qual foi medido; ou seja, os leitores precisam compreender as operações utilizadas pelo contador para produzir o lucro calculado (abordagem do operacionalismo).

O conhecimento da sintaxe contábil ajuda compreender as operações utilizadas para evidenciar o lucro contábil do período. A necessidade desse conhecimento acentua-se com a possibilidade de a contabilidade utilizar os accruals. Esses, sob as restrições da Convenção do Conservadorismo geram algumas questões quanto à qualidade do lucro contábil, enquanto medida do desempenho da eficiência empresarial (Costa, Teixeira, \& Nossa, 2002).

Almeida (2001, p. 10) comenta que o "enfoque clássico de medida em contabilidade é essencialmente quantitativista, apoiado no processo digráfico, o que limita o tamanho e o tratamento dos fatos econômicos, porque se apóia numa estrutura calculatória oriunda da aritmética". A partir deste pressuposto, origina-se a síndrome de exatidão, de forma que este reducionismo implica dificuldades na quantificação de informações de natureza subjetiva. Uma das dificuldades relaciona-se à presença dos accruals, pois contêm informações discricionárias e não discricionárias, que trazem implícito certo grau de subjetividade, suscitando estudos quanto ao poder preditivo do lucro contábil na orientação de decisões gerenciais futuras.

Uma das preocupações dos analistas das demonstrações contábeis consiste em saber se a empresa continuará operando de forma saudável, com liquidez e rentabilidade satisfatórias, e quais as perspectivas para o futuro de acordo com o ocorrido no passado. Portanto uma característica da informação contábil diz respeito a seu valor preditivo ou à capacidade de se fazer, por meio de sua leitura, projeções para o futuro próximo. Entretanto, dependendo da forma como é apresentada a informação, pode ter maior ou menor valor preditivo.

O adequado grau de abstração e refinamento dos procedimentos contábeis 
adotados, segundo Santos e Silva (2001), depende do objetivo da mensuração. Na elaboração das informações contábeis deve-se decidir quais procedimentos serão adotados para o cálculo dos números que comporão as demonstrações. Tais números precisam ser declarados, a fim de que os diversos usuários das informações possam usá-los como inputs em seus respectivos processos decisórios. Assim, entre outras formas de fazer estimativas e provisões, com vistas à elaboração das demonstrações contábeis, os usuários deveriam ponderar as implicações dos diferentes procedimentos contábeis adotados, no que se refere, por exemplo, ao método de depreciação, avaliação de estoques, provisão de devedores duvidosos, provisões para contingências, provisões trabalhistas.

Santos e Silva (2001) argúem que, naturalmente, determinar a relação entre as informações contábeis e as variáveis que afetam o processo de tomada de decisão de cada usuário não é tarefa fácil. Por exemplo, a relação entre os procedimentos contábeis adotados e o valor de mercado das ações não pode ser determinada somente por meio da observação se os preços das ações variam em função da mudança de procedimentos contábeis.

A estrutura conceitual da contabilidade, da qual os procedimentos de depreciações para determinação do lucro fazem parte, foi criada na tentativa de explicar a prática de contabilidade. Por conseguinte, nasceu com o interesse de prescrever como as empresas deveriam proceder no registro e na mensuração de suas transações, bem como evidenciar as informações contábeis.

O lucro como indicador do desempenho de uma empresa, utilizado para balizar o processo de tomada de decisão por parte dos agentes econômicos, consubstanciase como uma das principais preocupações das informações contábeis divulgadas aos usuários. Certamente, a origem do conceito de lucro está na teoria econômica; mas compete à contabilidade mensurá-lo; no entanto sua mensuração sempre foi controversa e, não raramente, encontra-se na literatura austeras inferências voltadas à real capacidade da contabilidade mensurar o resultado das operações das entidades.

A partir das considerações apresentadas, a premissa subjacente deste estudo fundamenta-se na suposição de que a função principal da contabilidade está imbricada na geração de informações relevantes e tempestivas para o processo decisório, sendo perfeitamente exeqüíveis as provisões e estimativas, embora estas possam ser intituladas de opiniões revestidas de certo grau de subjetividade. Portanto, analisa-se, por meio de tratamento estatístico, a influência dos accruals na correlação entre o lucro contábil e a variação do capital circulante líquido. Nesta análise está-se considerando as empresas que utilizam os accruals provenientes da depreciação, em face dos diversos métodos de cálculos, na apuração do lucro contábil. 
Pretende-se demonstrar que o processo contábil, ao dispor de alternativas para certos procedimentos contábeis, as quais não influem, em princípio, diretamente no caixa, abre nichos para manipulação do lucro contábil. Dessa maneira, ao analisar a eficiência empresarial por meio do lucro do período, torna-se prudente conhecer a sintaxe utilizada na geração das informações contábeis, a fim de propiciar maior credibilidade às decisões tomadas a partir destas informações.

No que se refere às limitações do estudo, foram considerados como accruals apenas as depreciações, em função da facilidade de identificação nas demonstrações contábeis. Além disso, devido a não publicação da Demonstração do Fluxo de Caixa das empresas pesquisadas utilizou-se a Variação do Capital Circulante Líquido da Demonstração de Origens e Aplicações de Recursos.

Quanto à organização do conteúdo, faz-se inicialmente uma incursão teórica nos aspectos conceituais dos accruals accounting. Depois, aborda o lucro contábil e o lucro econômico no processo de geração de informações para tomada de decisões e o impacto dos accruals na formação do lucro contábil. Após a fundamentação teórica, contempla-se a descrição e análise dos dados, bem como as considerações finais do estudo.

\section{Procedimentos Metodológicos}

O delineamento da pesquisa caracterizou-se como estudo exploratório, em fontes secundárias, com abordagem lógica dedutiva. De acordo com Tripodi, Fellin e Meyer (1981, p. 64), o estudo exploratório tem por finalidade principal "desenvolver, esclarecer e modificar conceitos e idéias, a fim de fornecer hipóteses pesquisáveis para estudos posteriores".

A população-alvo para estudo compreende as empresas apresentadas como as 500 Maiores e Melhores Empresas do Brasil, conforme pesquisa realizada pela Revista Exame no ano de 2002. Para a seleção da amostra adotou-se, inicialmente, o critério da acessibilidade, mas com a preocupação de reunir empresas que representassem todo o universo populacional. Dessa forma, considerou-se a Demonstração do Resultado do Exercício, a Demonstração de Origens e Aplicações de Recursos - DOAR e as Notas Explicativas do ano de 2002, extraída do site da Comissão de Valores Mobiliários - CVM (www.cvm.gov.br), de 50 empresas de diferentes setores. Em seguida, procedeu-se a seleção intencional da amostra, escolhendo-se dessas as que evidenciaram, de forma mais objetiva, os valores da depreciação do período, resultando em 30 empresas.

Quanto aos procedimentos sistemáticos para a descrição e explicação dos 
fenômenos, o estudo se desenvolveu num ambiente que preconizou a abordagem quantitativa. O método quantitativo, conforme Richardson (1999), caracteriza-se pelo emprego da quantificação tanto nas modalidades de coleta de informações, quanto no tratamento por meio de técnicas estatísticas. Desse modo, utilizou-se a técnica de análise descritiva, tendo como suporte ferramental estatístico o software Statistics 6.0 para análise das variáveis, ou seja, a correlação entre o lucro contábil e a variação do capital circulante líquido em detrimento do volume de accruals presente no período considerado.

\section{Aspectos Conceituais sobre os Accruals Accounting}

A expressão accruals tem sido usada no sentido de provisões ou estimativas. Genericamente, representam os elementos do resultado que, embora pelo regime de caixa já tenham sido efetivados, ainda não se atribuem dentro do período de apuração ou do regime de competência. De acordo com Stickney e Weil (2001, p. 791), o termo accrual está relacionado ao reconhecimento de despesa ou receita e do correspondente passivo ou ativo, em decorrência de um evento contábil. A ocorrência do evento em exame não se relaciona com a entrada ou saída de caixa; por exemplo: no final de determinado período, reconhece-se uma receita ou despesa de juros, independentemente dos juros terem sido recebidos ou pagos.

Glautier e Underdown (1976) explicam que o conceito de accruals pode ser entendido ao se fazer a distinção entre o recebimento de caixa e o direito de recebimento de caixa, e o pagamento de caixa e a obrigação legal de pagamento, porquanto, freqüentemente não há coincidência entre o direito e obrigação legal e a transferência de caixa. Segue-se, no entanto, que o profissional de contabilidade deve apurar a receita e a despesa contábil, e para certificar-se qual o montante de obrigação a pagar, realiza provisões. Similarmente, quando há pagamentos antecipados, estes devem ser excluídos e transferidos para o próximo período contábil, efetuando ajustes entre as contas.

Sloan et al. (2001) alicerçam a definição de accruals na classificação de fluxos de caixa, proposta no pronunciamento SFAS 95 do FASB. Neste pronunciamento, o FASB classifica os fluxos de caixa em atividades operacionais, de financiamento e de investimentos. As atividades de investimentos referem-se às relacionadas à aquisição e disposição de ativos produtivos; as atividades de financiamento são referentes à captação e reembolso de fontes de capitais; as atividades operacionais se referem às demais não relacionadas com as anteriores.

Ao reportar-se às atividades operacionais, explica que os fluxos de caixa destas atividades representam dinheiro de transações e outros eventos que entram na 
determinação do resultado líquido. Analogamente, Sloan et al. (2001, p. 7) concebem os accruals como "a diferença entre resultado líquido e dinheiro vivo dos fluxos de atividades operacionais".

Os accruals accounting - estimativas de contabilidade - têm despertado a atenção de diversos autores, entre os quais Chan et al. (2001), Sloan et al. (2001), Almeida (2001), Martinez (2001), Lopes (2002), Costa et al. (2002), Oliveira, Guerreiro e Securato (2002), Santos e Guerreiro (2003), destacando-os como um importante indicador de qualidade do lucro líquido e útil para estimação do resultado das empresas.

De acordo com Chan et al. (2001), os accruals accounting representam a diferença entre o lucro contábil de uma empresa e o seu fluxo de caixa subjacente. Neste caso, quanto maior o valor dos accruals, maior será a diferença entre o lucro contábil e o caixa gerado. Para eles, elevadas estimativas positivas de accruals indicam maiores lucros que os fluxos de caixa gerados pela empresa num determinado período. Esta não correlação entre lucros e fluxo de caixa, deve-se, a priori, aos Princípios Contábeis, de forma mais estrita ao Princípio da Realização da Receita e da Confrontação das Despesas, também denominado de Princípio da Competência, por obedecer ao regime de competência.

Os accruals, na explicação dada por Chan et al. (2001), fundamentam-se na premissa de que nas estimativas há informações quanto ao desempenho operacional da organização; como, por exemplo, as mudanças de critérios contábeis, nos inventários, diferentes métodos de cálculo da depreciação, reconhecimento de recebimentos e pagamentos futuros. Neste sentido, estudaram o poder preditivo dos accruals. Para isso, optaram por investigar se o retorno futuro das ações de algumas empresas mantinha relação com a qualidade atual dos lucros. Entre as conclusões entenderam que: a) o mercado pode ser temporariamente enganado, porque reage lentamente a estas informações; b) os accruals têm uma relação positiva com os lucros e negativa com o fluxo de caixa.

Outras considerações da pesquisa de Chan et al. (2001) são reportadas em Costa, Teixeira e Nossa (2002), entre as quais se destaca: a) o impacto potencial da manipulação dos retornos é mais visível nos grupos com elevados valores positivos de accruals. Entendem, para manter a expectativa dos investidores, que a administração poderia manipular os lucros das empresas que começassem a dar sinais de diminuição no crescimento dos lucros, como exemplo, esperando que as vendas aumentem num futuro próximo, decida aumentar os estoques para suportar o aumento nas vendas, gerando conseqüentemente, aumento nos accruals; b) as vendas não apresentaram crescimento suficiente para justificar o aumento nos estoques, ou seja, estas empresas não aumentaram estoques para atender a 
expectativas de aumento nas vendas, conotando uma intenção de manipulação nos lucros pela administração, o que resulta em elevados níveis de accruals.

Martinez (2001) explica que o registro dos accruals na contabilidade busca mensurar o lucro no sentido econômico, representando o efetivo acréscimo na riqueza patrimonial da unidade econômica, independentemente da movimentação financeira. O problema parece estar na intenção do gestor de aumentar ou reduzir, discricionariamente, o nível de accruals, com o objetivo de influenciar o lucro divulgado.

Aumento nos lucros, quando acompanhados por accruals e, portanto, redução no fluxo de caixa, é um indicador antecipado de deterioração no desempenho operacional futuro da empresa, acompanhado pelos baixos retornos das ações. De acordo com Lopes (2002, p. 40), o "resultado contábil é relevante, mas tem baixo poder explicativo. A relevância dos resultados contábeis também depende de condições gerais de funcionamento do mercado e do nível de eficiência deste".

Lopes (2002) comenta que alguns autores, como Ball e Brown (1972), Wilson (1986,1987), Sloan (1996), Bernard e Stober (1989), estudaram a reação do preço das ações das empresas aos componentes do fluxo de caixa e dos accruals do resultado. Ball e Brown (1972) mostraram que o fluxo de caixa não é tão bem sucedido como o resultado residual para prever alterações nos preços das ações. Wilson (1986 e 1987) identificou que a evidenciação subseqüente de fluxo de caixa tem valor incremental sobre a evidenciação do resultado residual. Bernard e Stober (1989) dizem que os conteúdos informativos do fluxo de caixa e do resultado residual variam de acordo com as condições gerais da economia. Por outro lado, Sloan (1996) aponta resultados contraditórios, afirmando que o mercado não diferencia os componentes dos accruals do resultado.

Hendriksen e Van Breda (1999, p. 206) argumentam que a primeira relação entre lucros contábeis e preços de títulos foi proporcionada por Ball e Brown em 1968. Seus resultados diziam, essencialmente, que os preços de títulos variam na mesma direção que os lucros contábeis, e esta afirmativa tem sido confirmada por várias vezes desde então. No entanto a correlação entre lucro e preço é imperfeita pois:

os preços captam o impacto de um conjunto de informações muito mais amplo do que o representado apenas por lucros contábeis. Por exemplo, os preços reagem a coisas tão exóticas como boatos de guerra e tão corriqueiras quanto a variação da taxa de juros de Letras do Tesouro. Um outro motivo para a falta de correlação perfeita é o fato de que algumas flutuações dos lucros contábeis resultam de mudanças de regras contábeis, sem qualquer implicação econômica imediata. Por exemplo, uma mudança de método de depreciação não possui qualquer efeito sobre os fluxos de caixa antes do imposto de renda. 
Resultados desse tipo de investigação são importantes, tanto na teoria quanto na prática da contabilidade. Segundo Lopes (2002, p. 42), há uma expectativa que os accruals forneçam informações adicionais ao fluxo de caixa e que sua presença, como método de depreciação e de reconhecimento de receitas e despesas, seja um mecanismo para que as administrações forneçam informações privadas sobre a empresa para o mercado. Segundo o autor, não se pode esperar que a evidenciação adicional do fluxo de caixa forneça informações mais relevantes do que aquelas fornecidas pelo resultado líquido. Visto que, sendo os accruals uma das características fundamentais do modelo contábil, "a verificação de sua irrelevância coloca em dúvida a própria utilidade da contabilidade no contexto do mercado de capitais".

Nessa perspectiva, Carvalho (2002 como citado em Lopes, 2002, p. xii) chama a atenção para um dos mais atrozes dilemas a ser desmistificado no campo da pesquisa contábil: o falso conflito entre fluxo de caixa e accruals:

infelizmente, não são poucos os críticos de regime de competência, que levantam argumentos de alto efeito sonoro ao afirmarem que o fluxo de caixa é um fato e as provisões são opiniões. Olhando-se desapaixonadamente essa questão, é fácil concluir que provisões, e o lucro delas resultantes são opiniões sim, e é correto que sejam, porém o profissional de campo contábil tem que ter a competência e a coragem de emiti-las, pois caso contrário estaríamos confinados a só medir a variação da riqueza patrimonial ao término dos empreendimentos, o que pode levar alguns séculos ou nunca ocorrer.

De forma mais abrangente, pode-se classificar qualquer ajuste contábil que resulte em diferença entre o resultado líquido e os fluxos de caixa como resultado do processo de contabilização dos accruals. Aumentos inesperados, e em proporções agressivamente desiguais aos períodos anteriores, podem levar a duas hipóteses que merecem atenção especial por parte dos investidores e acionistas das empresas: a) melhoria genuína da rentabilidade da empresa; e, b) contabilidade agressiva por parte dos gestores quanto à manipulação de resultados. Investigar o resultado contábil das empresas e, se necessário, ajustar o lucro líquido ou prejuízo pode ser relevante para melhorar a qualidade das informações evidenciadas nas demonstrações contábeis.

A contabilidade, como sistema de informação de suporte à tomada de decisões, deve ser capaz de identificar e comunicar os problemas potenciais que, no momento adequado, requerem respostas estratégicas. Na seqüência, são verificados os aspectos conceituais sobre a dicotomia entre lucro contábil e lucro econômico no processo de geração de informações para o processo decisório. 


\section{Lucro Contábil e lucro Económico no Processo de Geração de Informaçóes para Tomada de Decisóes}

A hipótese de que o lucro contábil, apurado a partir dos Princípios Contábeis, não guarda estreita relação com o significado de lucro econômico foi abordado veementemente na década de sessenta, sobretudo, por Solomon (1961) e Chang (1962). Ainda hoje, o conceito de lucro sob o regime de competência continua sendo questionado como uma medida fundamental. Entretanto, de acordo com Hendriksen e Van Venda (1999), do ponto de vista informacional, o lucro contábil descreve efetivamente a atividade empresarial, e os contadores continuam a dar ênfase em sua mensuração, assim como os analistas financeiros exigirem a publicação, seja em consequiência do desejo de contar com uma única medida do lucro, ou do reconhecimento da informação contida no cálculo do lucro contábil.

Segundo Catelli e Guerreiro (2001), o lucro contábil corresponde ao resíduo derivado do confronto entre a receita realizada e o custo consumido. Não obstante, Hendriksen e Van Breda (1999) aduzem que há algumas críticas quanto ao lucro contábil em sua forma tradicional: a) o conceito de lucro contábil ainda não se encontra claramente formulado; b) não há base teórica permanente para o cálculo e apresentação do lucro contábil; c) as práticas contábeis geralmente aceitas permitem variações na mensuração do lucro do exercício de empresas diferentes; e, d) as variações do nível de preços tem modificado o significado do lucro medido em termos monetários históricos.

Em face destas críticas, reconhecem que a mensuração do lucro contábil apresenta problemas conceituais e práticos consideráveis. Nesse sentido, sugestões têm sido propostas para amenizar esta lacuna, entre as quais se elenca a necessidade de dar ênfase ao processo de contabilização por competência do exercício; a defesa de um único conceito operacional de lucro que possa ser utilizado para distribuição de dividendos; diversos conceitos de lucros para finalidades distintas; e um conceito de lucro contábil que se aproxime do lucro econômico. Em geral, os críticos alegam que o lucro contábil não guarda relação com o significado do lucro no aspecto econômico.

O conceito de lucro econômico fundamenta-se no conceito de renda de Hicks (1984, p. 147), o qual define renda de um indivíduo como o "montante que uma pessoa pode consumir durante a semana e ainda esperar estar, no final da semana, na mesma situação em que estava no começo". Solomon (1961, p. 682) expõe que a renda no sentido dado por Hicks é o "montante pelo qual a riqueza líquida cresceu durante um período, considerando-se devidamente o valor que foi consumido ou gasto durante aquele tempo". Para adaptar esta definição de renda às empresas, Solomon (1961), no artigo Economic and Accounting Concepts 
of Income, fez alguns ajustes para dotá-la de personalidade jurídica. Assim, a renda das empresas é o montante pelo qual o patrimônio líquido cresceu durante um período, considerando-se devidamente novas contribuições de capital realizadas pelos seus proprietários e quaisquer distribuições feitas aos proprietários.

A crítica de Solomon (1961) diz respeito ao fato de que, embora o lucro econômico possa assemelhar-se ao conceito contábil de lucro líquido, na medida em que este último é a figura que faz a conexão entre o patrimônio líquido inicial e final da empresa; tal semelhança é puramente verbal. Corrobora com essa idéia o fato de o lucro econômico, no momento de avaliar o patrimônio líquido, capitalizar receitas futuras, enquanto o lucro contábil exige apenas avaliação dos ativos líquidos com base em seus custos não expirados.

Catelli e Guerreiro (2001, p. 84) explicam que, em termos econômicos, o lucro é visto como "a quantia máxima que a empresa pode distribuir como dividendos e ainda continuar tão bem ao final do período como estava no começo". De forma que esta expressão, continuar tão bem, está empregada no sentido de manter o capital intacto, em termos do valor descontado do fluxo de recebimentos líquidos futuros.

No ponto de vista econômico, Solomon (1961) observa que o aumento do patrimônio líquido da empresa, que constitui seu lucro, deve resultar de uma avaliação da empresa como um todo no início e no final do período no qual se deseja mensurar o lucro. Tal avaliação requer descontar, em cada data, os fluxos de recebimentos esperados menos os fluxos de pagamentos esperados, para o maior horizonte de tempo possível, de forma a obter o valor presente do fluxo líquido. Todavia tal conceito parece, do ponto de vista pragmático, pouco praticável, ao exigir um grau de precisão sobre-humano, além de não se eximir da possibilidade de mudança nas expectativas humanas sobre o futuro.

Sobre o método de formação do lucro econômico, Iudícibus (1966, p. 47) mostra que na ausência de pagamentos de dividendos e de novos aportes dos acionistas, o lucro seria mensurado "subtraindo-se da soma dos valores atuais das receitas líquidas que se espera auferir, desde o momento t1 até o horizonte, a soma dos valores atuais das receitas líquidas que se espera auferir, desde o momento anterior t0 até o horizonte". Dada essa conceituação, o lucro é visto na perspectiva da comparação de duas situações estáticas. Os valores atribuídos à composição patrimonial em t0 e t1 são expectativas de eventos futuros trazidos ao momento atual pelo processo de desconto. Por esse motivo, afirma que a conceituação econômica de lucro é essencialmente ex-ante, isto é, voltado para o futuro, ao passo que o contábil é ex-post, baseado no passado.

O conceito de lucro, segundo Martins (2000), depende da fixação dos objetivos 
que se deseja atingir. O fato é que, no longo prazo, o lucro contábil e o lucro econômico acabam por convergir para um único valor. Solomon (1961, p. 684) diz que, de fato, não se pode negar que, a longo prazo, o lucro contábil e o lucro econômico convergem. "Mas isso é um pobre consolo para os defeitos de mensuração do lucro no curto prazo. Todos os problemas da mensuração do lucro são resultado de nosso desejo de atribuir lucro a curtos períodos de tempo, arbitrariamente determinados".

No que se refere ao lucro como recurso para tomada de decisões, Hendriksen e Van Breda (1999, p. 217) apregoam que o lucro líquido de vários períodos pode ser útil para a elaboração de predições futuras da empresa, caso haja o cuidado necessário para incluir outras variáveis relevantes. Um aspecto crucial no impacto de lucros contábeis no processo decisório está relacionado ao conteúdo informacional dos dados de lucro. Por exemplo, algumas flutuações dos lucros contábeis resultam de mudanças de critérios contábeis, como no caso de alterações nos métodos de depreciação, mudanças dos métodos de avaliação de estoque, as considerações de provisões de passivos trabalhistas e contingências, de forma que não se pode negligenciar a possibilidade ilusionística de tratar os usuários do lucro contábil.

Sancovschi e Matos (2002) relatam que Bruns e Merchant (1990) submeteram aos leitores da Harvard Business Review um questionário, com treze perguntas, para avaliar suas opiniões sobre gerenciamento de lucros. Dentre a análise das respostas dadas pelos 649 leitores destacam que: (i) nenhuma prática foi unanimemente julgada como ética ou antiética; (ii) gerenciar lucros por meio da tomada de decisões operacionais é eticamente mais aceitável do que gerenciálos por meio da escolha de procedimentos contábeis específicos; (iii) gerenciar lucros para reduzi-los foi considerado mais aceitável do que gerenciar lucros para aumentá-los; e (iv) as escolhas de práticas contábeis para alcançar metas de lucro foram consideradas questionáveis ou, no máximo, infrações graves, isto é, as manipulações contábeis são condenáveis, porém não antiéticas.

O lucro, quando considerado um indicador de sucesso das empresas, de acordo com Santos e Silva (2001), revela a capacidade de arregimentar e organizar os limitados recursos sociais. Assim, entre outros fatores, a existência de lucro pode indicar que: a) a empresa está agregando valor aos recursos escassos que the foram disponibilizados; b) os clientes estão contentes, pois suas necessidades por determinado tipo de produto ou serviço estão sendo satisfeitas; c) a existência de um bom ambiente organizacional; e d) boa integração da empresa com o ambiente externo.

Catelli e Guerreiro (2001) enfatizam que um dos argumentos a favor do lucro é o fato de ser considerado a melhor medida de sucesso da administração de uma 
entidade de negócios em uma economia competitiva. Sob o ponto de vista dos detentores de capital, o lucro representa um guia para políticas de investimentos. Investidores cautelosos procuram otimizar o retorno de seu capital, e suas decisões são guiadas pelos lucros proporcionados pelos investimentos. De maneira que os investimentos mais atrativos são aqueles que prospectam maior valor presente dos futuros recebimentos por unidade monetária aplicada no negócio.

A análise dos conceitos e objetivos do lucro líquido indica que um único conceito de lucro é incapaz de atender a todas as finalidades de maneira satisfatória. Hendriksen e Van Breda (1999) ressaltam que o conhecimento de medidas distintas do lucro de uma empresa pode ser útil para finalidades diversas. No entanto acreditam haver alguma vantagem na aceitação geral de um conceito abrangente de lucro líquido para fins de divulgação externa. Assim, afirmam que o objetivo principal da divulgação do lucro é o fornecimento de informações úteis aos interessados nas informações financeiras. Em específico a divulgação do lucro atua como: a) instrumentos de predição da trajetória futura da empresa ou dos futuros dividendos; b) medida de eficiência da gestão da empresa; e c) medida de desempenho e orientação para decisões gerenciais futuras.

Por considerar que os aspectos norteadores do cálculo do lucro empresarial envolvem um conjunto considerável de variáveis, a pesquisa circunscreve-se a investigar a influência dos accruals na determinação do lucro contábil. Mais precisamente, se há uma correlação entre o lucro contábil e variação do capital circulante líquido das empresas em detrimento dos níveis de accruals relativos à depreciação considerada para formação do lucro contábil, uma vez o lucro ser considerado como um dos referenciais para mensuração da eficiência e eficácia gerencial.

\section{Os Accruals na formação do lucro Contábil}

A diferença preponderante entre o lucro contábil e o econômico reside na consideração do Princípio da Competência, em decorrência do aspecto temporal utilizado na mensuração do resultado do período. A discussão sobre o lucro contábil e econômico estaria resolvida ao considerar um período de tempo suficientemente longo, pois as mudanças no valor do patrimônio das empresas também estariam refletidas no lucro contábil.

A questão circunscreve-se, todavia, na relevância das informações geradas pelo lucro contábil ao final da vida das empresas, onde todos os percalços já teriam sido transpostos e para o processo decisório pouco serviria a contabilidade, 
a não ser para mensurar resultados passados. Por isso, conforme Iudícibus (2000, p. 49), a contabilidade tem a responsabilidade de "atribuir parcelas, mesmo que aproximadas, de seu resultado total, aos vários períodos".

De acordo com Hendriksen e Van Breda (1999), compete à contabilidade gerar informações sobre a empresa, de forma a permitir que os próprios usuários façam seus julgamentos quanto ao futuro do empreendimento. A atribuição de valores estimados e provisionados na contabilidade reveste-se de grande responsabilidade, uma vez que influenciarão diretamente o resultado contábil líquido da empresa. Estes, por sua vez, podem causar equívocos interpretativos por parte dos tomadores de decisões que não conhecem o processo preparatório das demonstrações financeiras.

O Framework for the Preparation and Presentation of Financial Statements do IASB - International Accounting Standard Board menciona que os efeitos das transações e outros eventos são conhecidos quando ocorrem (e não quando os numerários ou seus equivalentes são recebidos ou pagos). Observando-se, conseqüentemente, os pressupostos básicos do Regime de Competência da contabilidade, devem ser lançados nos registros contábeis e reportados nas demonstrações contábeis nos períodos a que pertencem (Costa et al., 2002).

Para observar o Regime de Competência, o processo de mensuração contábil exige estimativas de valores futuros incertos, como por exemplo, a depreciação, que se consubstancia na estimação da contribuição dos imobilizados para a formação do custo da produção do período. Nesse particular, deve-se considerar que os diversos métodos de depreciação levam a valores diferentes e, logo, a resultados divergentes no curto prazo (Costa et al., 2002).

Tais diferenças conflitam nos conceitos discricionários e não discricionários dos accruals. Assim, a possibilidade de escolher, o método da depreciação, levanta questionamentos quanto à intenção de manipular o resultado contábil. Por esta situação é possível questionar a qualidade do lucro contábil no processo de mensuração da eficiência empresarial por meio do lucro do período. Na sequiência, demonstra-se estatisticamente a correlação do lucro contábil com a variação da capital circulante líquido de algumas empresas, quando estas utilizam accruals referente a depreciações.

\section{Descrição e Análise dos Dados Coletados}

A pesquisa considerou como população alvo as 500 Maiores e Melhores Empresas do Brasil, conforme coleta de dados realizada na Revista Exame, edição 
de 2002. O processo de coleta de dados envolveu, inicialmente, a seleção intencional de 50 empresas dos seguintes setores: alimentício, química e petroquímica, siderurgia e metalurgia, comércio varejista, mineração, automotivo, eletroeletrônico e papel celulose. Uma vez selecionada a amostra, buscou-se a Demonstração do Resultado do Exercício, a Demonstração de Origens e Aplicações de Recursos e as Notas Explicativas dessas empresas, referentes ao ano de 2002, publicadas na homepage da Comissão de Valores Mobiliários (CVM). Todas as empresas são sociedades anônimas de capital aberto, e obrigatoriamente disponibilizam suas demonstrações contábeis à Comissão de Valores Mobiliários.

Da amostra de 50 empresas selecionada e verificada inicialmente, apenas 30 empresas puderam compor a amostra intencional, em função de as demais empresas não evidenciarem de forma objetiva os valores concernentes à depreciação do período, dados estes essenciais à aplicação da metodologia proposta. O Quadro 1 mostra as empresas selecionadas para análise da correlação entre o lucro contábil e a variação do capital circulante líquido, considerando a depreciação como um dos itens que compõem os accruals.

\section{Quadro 1: Empresas Participantes da Amostra em (Mil Reais)}

\begin{tabular}{|c|c|c|c|c|}
\hline Empresas & Depreciação & $\begin{array}{c}\text { Lucro/Prejuízo } \\
\text { Líquido }\end{array}$ & \begin{tabular}{|c|} 
Lucro/prejuízo \\
Líquido ajustado
\end{tabular} & $\begin{array}{c}\text { Variação do } \\
\text { CCL }\end{array}$ \\
\hline Acesita S/A & -3.415 & -320.900 & -317.485 & -310.881 \\
\hline Aços Villares S/A & -35.484 & -45.497 & -10.013 & -32.529 \\
\hline Adubos Trevo S/A & -9.622 & 44.911 & 54.533 & 9.438 \\
\hline Avipal S/A & -35.472 & 7.132 & 42.604 & -53.507 \\
\hline Bompreço Bahia S/A & -25.729 & -33.323 & -7.594 & 9.947 \\
\hline Comgás S/A & -42.584 & 107.745 & 150.329 & -808 \\
\hline Cia Brasileira de Distribuição S/A & -379.934 & 245.122 & 625.056 & -218.252 \\
\hline Cia Suzano de Papel Celulose & -43.045 & 104.430 & 147.475 & -717.517 \\
\hline Cosipa S/A & -11.810 & -548.655 & -536.845 & -726.273 \\
\hline CSN S/A & -619.322 & -218.615 & 400.707 & 2.095 .518 \\
\hline Drogasil S/A & -7.937 & 8.022 & 15.959 & 9.651 \\
\hline Electrolux do Brasil S/A & -13.107 & -56.743 & -69.850 & 126.093 \\
\hline Embraer S/A & -13.121 & 1.202 .066 & 1.188 .945 & -460.702 \\
\hline Eucatex S/A & -18.772 & -33.366 & -14.594 & -13.041 \\
\hline Latasa S/A & -24.796 & 236.840 & 212.044 & -111.424 \\
\hline Lojas Americanas S/A & -32.642 & 103.086 & 135.728 & 111.896 \\
\hline Lojas Renner S/A & -41.571 & -97.077 & -138.648 & 15.092 \\
\hline Magnesita S/A & -15.174 & 99.346 & 84.172 & 34.587 \\
\hline Marcopolo S/A & -7.136 & 56.868 & 49.732 & 109.571 \\
\hline Metalúrgica Gerdau S/A & -150 & 434.028 & 433.878 & -29.451 \\
\hline Multibras S.A & -10.733 & 131.181 & 141.914 & 75.243 \\
\hline Ponto Frio S/A & -23.156 & 35.785 & 58.941 & -153.964 \\
\hline Politeno Ind. Com S/A & -3.482 & 45.596 & 49.078 & 57.325 \\
\hline Ripasa S/A & -93.978 & 92.691 & 186.669 & -247.362 \\
\hline Rhodia-Ster S/a & -179 & -63.885 & -63.706 & -13.105 \\
\hline Sadia S/A & -10.831 & 1.263 .688 & 1.274 .519 & 307.395 \\
\hline Seara Alimentos S/A & -2.094 & 78.978 & 81.072 & 3.268 \\
\hline Tigre S/A & -18.772 & 95.091 & 113.863 & 20.572 \\
\hline Usinas Sid. Minas Gerais S/A & -199.358 & -321.125 & -520.483 & -134.032 \\
\hline Vigor S/A & -968 & -31.625 & -32.593 & 1.328 \\
\hline
\end{tabular}


A depreciação, variável dependente, foi calculada, pelo método linear para todas as empresas, conforme esclarecimentos disponíveis nas Notas Explicativas das demonstrações contábeis. O lucro ou prejuízo líquido do período, variável independente, é o evidenciado na Demonstração do Resultado do Exercício. O lucro ou prejuízo líquido ajustado, variável dependente, é apurado pela adição do valor da depreciação do período, por considerar que este não tem, em princípio, efeito direto sobre o fluxo de caixa. A variação do capital circulante líquido referese ao valor publicado na Demonstração das Origens e Aplicações de Recursos. Todos os valores tratados na pesquisa não consideram os efeitos inflacionários.

Entende-se que a variação do capital circulante líquido, evidenciado na DOAR, apresenta, de forma sumariada, as informações de operações de financiamento e investimento durante o exercício e mostra as alterações na posição financeira da empresa, ampliando o conceito de recursos financeiros utilizado no fluxo de caixa. Segundo a Fundação Insitituto de Pesquisas Contábeis, Atuariais e Financeiras [FIPECAFI] (2000, p. 337), o significado de recursos da DOAR não é simplesmente o dinheiro ou as disponibilidades. Este envolve um conceito mais amplo, pois representa o capital de giro líquido, obtido pela subtração do ativo circulante com o passivo circulante.

Neste particular, a variação do capital circulante líquido não deve ser confundida somente com os fluxos das disponibilidades, como apregoado na Demonstração de Fluxo de Caixa. As informações da DOAR são mais abrangentes, não só por conterem variações do Capital Circulante Líquido, em substituição das variações de caixa, mas por representarem a demonstração das mutações na posição financeira total das empresas. Tal pressuposto corrobora o conceito de lucro econômico de Solomon (1961), quando se refere ao lucro como o valor que se pode consumir no final de um período e ainda estar, no final deste, como no início do período.

O lucro contábil e lucro econômico, no longo prazo, conforme Martins (2000), convergem para o caixa. Assim, deve-se mostrar que um ativo possui, além das disponibilidades e das aplicações de caixa efetuadas, os direitos que estão para se transformarem em caixa e ainda que um ativo possui bens que estão representando o montante de caixa desembolsado ou a ser desembolsado em função de sua aquisição. O passivo, por sua vez, representa valores a desembolsar futuramente. Logo, todos os itens do Balanço têm ligação com o fluxo de caixa. Dessa forma, a consideração da variação do capital circulante líquido está empregada no sentido de mutação da posição financeira da empresa em determinado período de tempo considerado para análise.

A variável independente, segundo Kerlinger (1980), é aquela que se supõe influenciar outra variável, denominada variável dependente. A constituição de 
depreciação no resultado do exercício produz aumento no saldo de depreciação acumulada, afetando diretamente o lucro residual do exercício e, conseqüentemente, modifica a série histórica da empresa, o que pode causar distorções semânticas no resultado apurado, dependendo do método de depreciação utilizado nos procedimentos contábeis.

A análise da eficiência empresarial, com base no lucro ou prejuízo do período e nos cálculos prospectivos do lucro empresarial, pode ser influenciada pela suscetibilidade de os gestores das empresas manipularem o resultado contábil, em detrimento da faculdade de se adotarem diferentes procedimentos contábeis para um mesmo fato. Vale lembrar que não se questionam os métodos de depreciação possíveis, mas busca-se mostrar que a utilização de accruals, de um ou outro método, leva a resultados diferentes e que esta discricionariedade da variável depreciação pode, em alguns casos, ser um artifício para manipulação de resultados.

Quanto aos procedimentos estatísticos para determinar a intensidade da relação entre as variáveis, fez-se, em um primeiro momento, análise entre a variação do capital circulante líquido e o lucro líquido ou prejuízo do período. Com este cálculo obteve-se o coeficiente de correlação de $-0,0477$, como reportado graficamente na Figura 1.

\section{Figura 1: Gráfico de Correlação entre Lucro Líquido e a Variação do CCL}

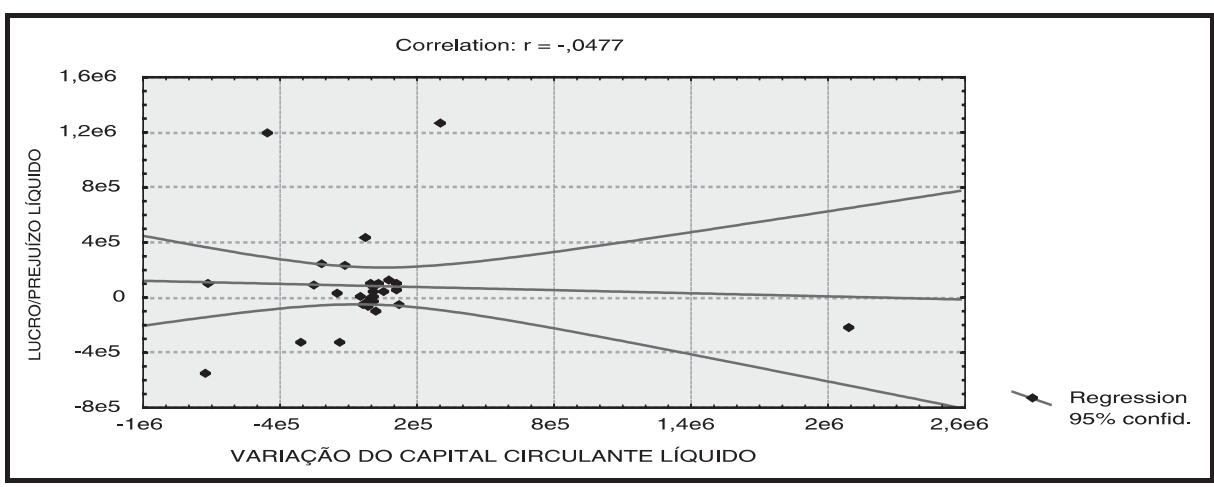

De acordo com Gil (1999), quando este coeficiente for igual a 0,00 para duas varáveis absolutamente independentes entre si, não existe nenhuma relação entre as variáveis. No caso de o coeficiente de correlação ser $+1,00$ significa que há forte associação positiva entre as variáveis, sendo o inverso também verdadeiro. Na situação estudada, o coeficiente de correlação r: -0,0477 conota que o lucro ou prejuízo líquido contábil (incluindo a dedução da depreciação) possui baixa correlação negativa quando comparado à variação do capital circulante líquido. 
Por outro lado, ao se analisar a correlação entre o lucro ou prejuízo líquido ajustado pela adição da depreciação, que anteriormente havia sido subtraída, obtevese um coeficiente de correlação de r: 0,19089. Na Figura 2 representa-se graficamente esta correlação.

Figura 2: Gráfico de Correlação entre Lucro Líquido Ajustado e a Variação do CCL

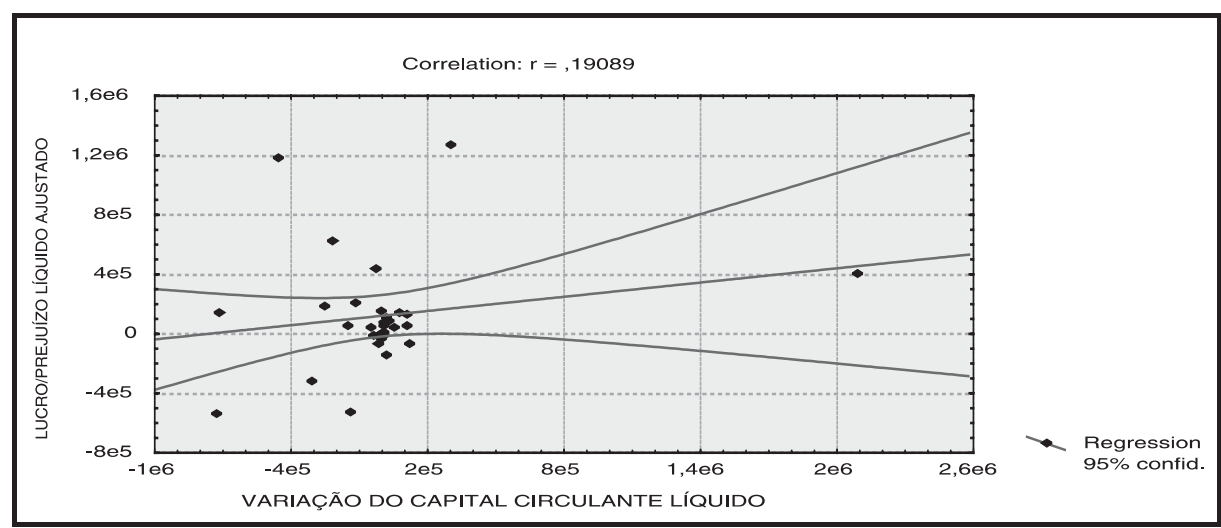

Nota-se, apesar da baixa correlação positiva, uma diferença entre os dois coeficientes, em função do acréscimo da variável dependente (depreciação), a qual altera o resultado contábil residual. Significa dizer que os accruals são positivamente correlacionados com o lucro ou prejuízo, quando comprados à variação do capital circulante líquido.

Ao considerar que o usuário da informação contábil desconhece a sintaxe de apuração do resultado contábil, pode conotar pelo primeiro coeficiente de correlação de r: - 0,0477 não ser atrativo para investimentos nas empresas estudadas. Pela reincorporação da depreciação ao lucro residual, o coeficiente de r: 0,19089 denota maior atratividade, quando se restringe o conceito de lucro como medida para determinar a eficiência empresarial. Na ótica da análise prospectiva do lucro para definir a opção por investimentos futuros dos acionistas, entende-se que os accruals estão revestidos de alto valor preditivo no processo decisório. Portanto os procedimentos contábeis que abarcam os accruals suscitam análise acurada para verificar a intencionalidade subjacente da administração em manipular resultados para atrair aportes de capital ou outros fins.

Costa et al. (2001) mencionam que os accruals podem denotar o impacto potencial da manipulação dos retornos. Uma provável explicação para este fato é que, para manter as expectativas dos investidores, a administração teria mais incentivos em manipular os lucros, quando estes começarem a acenar reduções de crescimento. 
Os accruals, consubstanciados como característica fundamental do modelo contábil, podem influenciar diretamente a mensuração da eficiência empresarial, quando esta for respaldada no resultado líquido do período. Faz-se necessário considerar que, segundo Hendriksen e Van Breda (1999), os administradores reagem ao que supõem ser o comportamento dos investidores e credores em face do lucro publicado. Muito embora, o lucro, apurado sob o enfoque sintático, se baseie nos Princípios Contábeis Geralmente Aceitos, o fenômeno de feedback acaba por afetar as escolhas dos métodos de contabilidade pelos gestores, quando houver mais de um procedimento aceito para o mesmo fato. Assim, o lucro líquido apurado em vários períodos contábeis pode ser útil para a elaboração de predições das operações futuras da empresa.

\section{Considerações Finais}

O conceito de lucro apropriado para a divulgação das atividades de uma empresa é determinado pelos objetivos dos usuários e, sobretudo, pela capacidade destes em analisar semanticamente os números sintetizados nas demonstrações contábeis. Não se pode negligenciar a vantagem da aceitação de um conceito abrangente de lucro líquido para fins de divulgação externa. A partir do conhecimento da sintaxe contábil adotada pelos responsáveis sobre as informações geradas, o processo interpretativo precisa considerar as possíveis discrepâncias causadas pelos itens discricionários incluídos no resultado do período.

O lucro contábil, como resultante do somatório de itens positivos e negativos, traz em seu bojo o conteúdo interpretativo. Por conseguinte, estes itens carecem de significado, muito embora guardem informações relevantes para os usuários das informações contábeis.

No que diz respeito à análise por meio de tratamento estatístico da correlação entre o lucro contábil e a variação do capital circulante líquido em empresas que utilizam accruals, de forma mais centrada, os decorrentes da depreciação, observou-se que há uma correlação positiva ao ajustar o resultado residual pela respectiva depreciação do período. Isto reforça a premissa de que o desconhecimento da composição do resultado pode influenciar positiva ou negativamente as interpretações a partir desta informação.

A apuração do resultado líquido como medida para determinar a eficiência empresarial requer a comparação com certo padrão. Esta avaliação é revestida de subjetividade; mas, como ponto de partida, pode ser feita com o resultado do período dos anos anteriores ou por meio de comparações com empresas de setores equivalentes. 
Por fim, ressalta-se a relevância das informações geradas pelo lucro contábil ao longo do ciclo de vida das empresas como medida essencial no processo decisório. Aguardar a mensuração do resultado do empreendimento para o término do ciclo de vida das organizações, onde todas as decisões já teriam sido transpostas, de pouca utilidade teria a contabilidade, a não ser para mensurar resultados passados. Isto reforça a concepção da contabilidade em buscar procedimentos para atribuir parcelas proporcionais de seu resultado, mesmo que revestidas de subjetividade e aproximações.

\section{Artigo recebido em 30.04.2004. Aprovado em 22.08.2004.}

\section{Referencias Bibliográficas}

Almeida, J. J. M. de (2001, julho/setembro). Risco e paradigma da auditoria. Revista Revisores e Empresas (14), pp. 15-16, Rio de Janeiro. Recuperado em 10 abril, 2003, de http:// www.amprotec.gov.br

Ball, R., \&

Brown, P. (1968, Autumn).

An empirical evaluation of accounting income numbers. Journal of Accounting Research, (6), pp. 159-178.

Ball, R., \&

Brown, P. (1972, April.).

The Theory of Value and Earnings, and an Introduction to the Analysis Based Valuation with Changing Interest Rates. The Accounting Review. Recuperado em 12 abril, 2003, de http://www.pcarey.asu.edu

Bernard, V., \&

Stober, T. (1989, October).

The nature and amount if information reflects teed in cash flows. The Accounting Review, pp. 624-652.
Bruns, W. J., \&

Merchant, K. A. (1990, August).

The dangerous morality of managing earnings. Management Accounting, 72(2), 22-25.

Catelli, A., \&

Guerreiro, R. (2001).

Mensuração do resultado econômico. In A. Catelli (Coord.). Controladoria: uma abordagem de gestão economia GECON (pp. 81-109.). São Paulo: Atlas.

Chan, E. C. (1962, October).

Business Income in accounting and economics. The Accounting Review, p. 637.

Chan, L. K., Jegadeesch, N., \& Lakonishok, J. (2001, January).

Earnings quality and stock returns: the evidence from accruals. Recuperado em 20 março, 2003, de http://www.fin.ntu.edu 
Costa, A. C. O. de,

Teixeira, A. J. C., \&

Nossa, V. (2002).

Conservadorismo, accruals e qualidade dos lucros contábeis. Anais do Encontro Nacional dos Programas de Pós-Graduação em Administração, Salvador, BA, 26.

Editora Abril (2002).

Revista Exame: melhores \& maiores. São Paulo, SP: Autor.

Financial Accounting Standards Board. (1978).

Impact on corporate risk and insurance management (Statement of financial accounting standards n 5). Stamford, CT.

Fundação Instituto de Pesquisas Contábeis, Atuariais e Financeiras (2000). Manual de contabilidade das sociedades por ações (5th ed.). São Paulo: Atlas.

Gil,A.C. (1999).

Métodos e técnicas de pesquisa social (5th ed.). São Paulo: Atlas.

Glautier, M.W.E., \&

Underdown, B. (1976).

Accounting theory and practice (5th ed.). Great Britain-London: Pitman Publishing Limited.

Hendriksen, E. S., \&

Van Breda, M. F. (1999).

Teoria da contabilidade. São Paulo: Atlas.

Hicks, J. R. (1984).

Valor e capital. São Paulo: Abril Cultural.
Iudícibus, S. de (1966).

Contribuição à teoria dos ajustamentos contábeis. Tese de Doutorado. Faculdade de Economia, Administração e Contabilidade, Universidade de São Paulo, São Paulo, Brasil.

Iudícibus, S. de (2000).

Teoria da contabilidade (6th ed.). São Paulo: Atlas.

Kelinger, F. N. (1980).

Metodologia da pesquisa em ciências sociais: um tratamento conceitual. São Paulo: EPU.

Lopes, A. B. (2002).

A informação contábil e o mercado de capitais. São Paulo: Pioneira Thomson Learning.

Martinez, A. L. (2001).

Gerenciamento dos resultados contábeis: estudo empírico das companhias abertas brasileiras. Tese de Doutorado. Faculdade de Economia, Administração e Contabilidade, Universidade de São Paulo, São Paulo, Brasil.

Martins, E. (2000, julho/dezembro).

Avaliação de empresas: da mensuração contábil à econômica. Revista Contabilidade e Finanças, 13(24), 28-37.

Oliveira, E. F. de,

Guerreiro, R., \&

Securato, J. R. (2002).

Uma proposta para avaliação da empresa em condições de risco com base no modelo de Ohlson. In Anais do Encontro Nacional dos Programas de Pós-Graduação em Administração, Salvador, BA, 26. 
Richardson, R. J.,

Souza Peres, J. A. de,

Wanderley, J. C. V.,

Correia, L. M., \&

Melo Peres, M. de H. (1999).

Pesquisa social: métodos e técnicas (3rd ed.). São Paulo: Atlas.

Santos, A. dos, \&

Silva, A. S. dos (2001).

Lucro contábil x lucro econômico: a validade do princípio da realização da receita. Anais da Asian Pacific Conference on International Accounting Issues. Rio de Janeiro, RJ, 13.

Santos, E. S., \&

Guerreiro, R. (2003, março).

Mensurando o resultado no ciclo decisório integral: da estratégia ao caixa. Revista do Conselho Regional de Contabilidade de São Paulo, (23), pp. 48-64.

Sloan, R. G. (1996, July).

Do stock prices reflect information in accruals and cash flows about future earnings? The Accounting Review. Recuperado em 10 abril, 2003, de http:/ /www.umi.com/proquest

Sloan, R. G.,

Dechow, P. M., \&

Hutton, A. P. (2001, January).

An empirical assessment of the residual income valuation model. Journal of Accounting and Economics (26), pp. 1-34, Recuperado em 12 abril, 2003, de http:// www.sciencedirect.com.
Sancovschi, M., \&

Matos, F. F. J. (2002).

Gerenciamento de lucros: o que pensam administradores, contadores e outros profissionais de empresas no Brasil? Anais do Encontro Nacional dos Programas de Pós-Graduação em Administração, Salvador, BA, 26.

Solomon, D. (1961, July).

Economic and accounting concept of income. The Accounting Review, pp. 681-698.

Stickney, C. P., \&

Weil, R. L. (2001).

Contabilidade financeira: uma introdução aos conceitos, métodos e usos. São Paulo: Atlas.

Tripodi, T.,

Fellin, P., \&

Mayer, H. (1981).

Análise da pesquisa social. Rio de Janeiro: Francisco Alves.

Wilson, G. (1986, April).

The relative information content of accrual and cash flows: combined evidence at the earnings announcement and annual release date. Studies on alternatives measures of accounting income. Journal of Accounting Research, pp.165-200.

Wilson, G. (1987, April).

The incremental information content of the accrual and funds components of earnings after controlling for earnings. The Accounting Review, pp. 293-322. 